\title{
Hypertonic milk replacers increase gastrointestinal permeability in healthy dairy calves
}

\section{Juliette Wilms, ${ }^{*}$ Harma Berends, and Javier Martín-Tereso}

Trouw Nutrition Research and Development, PO Box 299, 3800 AG, Amersfoort, the Netherlands

\begin{abstract}
Hypertonic milk replacers are commonly used in animal production systems and their effect on the gastrointestinal system of young animals is insufficiently studied. Total lactose inclusion or its partial replacement with dextrose increases intestinal osmotic pressure, which may compromise gastrointestinal barrier function. In this experiment, we investigated the effect of increased osmolality of calf milk replacer (CMR) on gastrointestinal permeability in 30 Holstein Friesian (n $=17)$ or crossbred $(\mathrm{n}=13)$ bull calves. The osmolality of CMR increased as result of a gradual replacement of lactose by monosaccharides (dextrose and galactose). Calves were acquired from dairy farms that followed a standardized protocol for colostrum management, including 3 feedings of colostrum in the first $24 \mathrm{~h}$. Calves were then transported to the research facility between 0 and $3 \mathrm{~d}$ of age, fed a milk replacer with $0 \%$ dextrose twice daily for the first 2 wk of age, and subsequently exposed to their respective treatments from 3 until 7 wk of age. Meal size was $3.2 \mathrm{~L}$ at 3 wk of age and increased to $3.5 \mathrm{~L}$ at 7 wk of age. No solids were provided throughout the study and calves had ad libitum access to water. Treatments included 4 levels of dextrose inclusion (replacing lactose): $0 \%$ $(\mathrm{L} 1, \mathrm{n}=5), 13.3 \%(\mathrm{~L} 2, \mathrm{n}=5), 26.7 \%(\mathrm{~L} 3, \mathrm{n}=5)$, and $40 \%(\mathrm{~L} 4, \mathrm{n}=5)$ and an additional treatment $(\mathrm{G}+\mathrm{D}, \mathrm{n}$ $=10$ ) that included $20 \%$ galactose and $20 \%$ dextrose and matched the galactose supply of L1 and the osmolality of L4. Carbohydrates were exchanged based on hexose equivalents. Across treatments, the estimated osmolality ranged from 439 (L1) to $611 \mathrm{mOsm} / \mathrm{kg}$ (L4 and $\mathrm{G}+\mathrm{D})$. Gastrointestinal permeability was assessed by fractional urinary recovery of indigestible markers (lactulose, D-mannitol, and Cr-EDTA) delivered as a single dose at 3 and 7 wk of age. Marker recoveries were expressed as percentage of oral dose and assessed in 6-h and 24 -h quantitative urinary collections. Increasing
\end{abstract}

Received June 22, 2018.

Accepted September 19, 2018.

*Corresponding author: juliette.wilms@trouwnutrition.com the osmolality of the CMR linearly increased urinary Cr-EDTA and lactulose recoveries at 3 and $7 \mathrm{wk}$ of age. Lactulose and Cr-EDTA recoveries did not differ between $\mathrm{G}+\mathrm{D}$ and L4, suggesting that the source of monosaccharide (dextrose and galactose) in CMR had no effect on gastrointestinal permeability. The observed increase in gastrointestinal permeability to large molecules (Cr-EDTA and lactulose) with increased osmolality suggests that hypertonic CMR may compromise gastrointestinal barrier function.

Key words: calf, osmolality of milk replacer, gastrointestinal permeability

\section{INTRODUCTION}

When considering milk feeds, osmolality (expressed in $\mathrm{mOsm} / \mathrm{kg}$ ) depends on the presence of osmotically active particles dissolved in solution, including electrolytes, oligo- and monosaccharides, AA, and fatty acids (Pearson et al., 2013). Commercial calf milk replacers (CMR) often contain higher levels of minerals (ash fraction) and lactose than bovine raw milk. Lactose levels in CMR are usually as high as 42 to $45 \%$ of DM compared with $35 \%$ DM for whole milk. Milk replacers fed to calves present a wide range in the percentage of solids per liter of solution, which can vary from 12.5 to $20 \%$. Consequently, the osmolality of CMR can range from slightly hypertonic (just above $300 \mathrm{mOsm} / \mathrm{kg}$ ) to highly hypertonic $(>450 \mathrm{mOsm} / \mathrm{kg})$. Additionally, mixing errors and feeding practices such as the addition of electrolyte powder on top of the milk, mixing CMR powder directly into whole milk, and colostrum supplement mixed into colostrum may increase the osmolality of the solution above $600 \mathrm{mOsm} / \mathrm{kg}$ (McGuirk, 2003). In comparison, osmolality of raw bovine milk is an isosmotic feed maintained close to $300 \mathrm{mOsm} / \mathrm{kg}$ (Davies and White, 1960; Cerbulis and Farrell, 1976; McGuirk, 2003).

The effects and tolerance boundaries of osmolality on gastrointestinal health of neonatal animals are not well understood. Previous work from Goldblum et al. (1981) showed that the osmolality of the feed itself was not a major determinant of the osmolality of the con- 
tents of the stomach or proximal and distal intestine in neonatal dogs. Indeed, as a response to exposure with hypertonic fluids, gastric emptying is delayed to reduce the osmolality of luminal and gastric contents by secretion of hypotonic fluids (Pearson et al., 2013). In addition, Szabo and Fewell (1990) showed that hypertonic solutions (up to $874 \mathrm{mOsm} / \mathrm{kg}$ ) did not induce significant motor dysfunction on the intestinal motility of neonatal pigs. However, Norris (1973) showed that a hypertonic dye (sodium diatrizoate) with an osmolality of $1,560 \mathrm{mOsm} / \mathrm{kg}$ caused a rapid decrease in the height and width of villi as well as a decrease in the height of epithelial cells. According to Kertz and Loften (2013), increased osmolality of milk replacer can lead to digestive disturbances. An increase in osmolality of milk feeding (milk replacer or addition of milk balancer to whole milk) can affect water absorption by the intestines, leading to an increased incidence of diarrhea in calves (Glosson et al., 2015). Although reference values are not well established, fluids with an osmolality above $600 \mathrm{mOsm} / \mathrm{kg}$ should be offered with caution (McGuirk, 2003), because the gradient is no longer as effective, and absorption in the small intestine is inhibited, possibly leading to osmotic diarrhea (Floren et al., 2016).

Current infant nutrition recommendations propose that the osmolality of enteral feeds for infants should not exceed $450 \mathrm{mOsm} / \mathrm{kg}$ (which approximates to an osmolarity of $400 \mathrm{mOsm} / \mathrm{L}$ ), a figure based on a historical consensus, rather than on experimental evidence (Pearson et al., 2013). Exposure to hypertonic solutions has been associated with loss of mucosal integrity in infants with a gastrointestinal tract compromised by extreme prematurity (Pearson et al., 2013). One explanation is the lack of ability of preterm infants to make normal adaptive responses (Pearson et al., 2013). Hypertonic milk replacer meals might therefore induce intestinal injuries when additional risk factors, such as prematurity, already exist (Pearson et al., 2013). Concentration and composition of milk replacers might therefore be as important to calf health as the quality and total amount of nutrients offered (Floren et al., 2016).

The gastrointestinal tract serves the dual role of absorbing valuable nutrients while preventing infiltration of unwanted compounds and molecules (Mani et al., 2012). Intestinal barrier function and intestinal permeability (IP) play an important role in health, and alteration of the gut barrier seems to have multiple consequences facilitating the onset of a variety of diseases (Bischoff et al., 2014). In animal production systems, gastrointestinal tract barrier function is known to be compromised during diarrhea (Klein et al., 2008), weaning (Moeser et al., 2007; Wood et al., 2015), heat stress
(Baumgard and Rhoads, 2013; Pearce et al., 2013), and rumen acidosis (Khafipour et al., 2009; Minuti et al., 2014). The direct consequence of intestinal barrier dysfunction is the increased leakage of luminal antigens into the bloodstream, with the potential to initiate an inflammatory response (Kvidera et al., 2017).

Lactulose-D-mannitol and Cr-EDTA permeability tests have been validated to assess gut integrity in humans (Andre et al., 1987; Jalonen, 1991) and in other species, including dogs (Hall and Batt, 1991; Quigg et al., 1993), rats (Turner et al., 1988), and calves (Klein et al., 2007, 2008; Araujo et al., 2015; Wood et al., 2015). A permeability test is a noninvasive diagnostic tool that provides information on the integrity of the mucosa and on its protective barrier function and may help to predict responses of the intestines to many potentially harmful stimuli (e.g., physiological, pharmaceutical, and nutritional; Klein et al., 2007).

Thus, the objective of this study was to assess the effect of increased osmolality of milk replacer on gastrointestinal permeability in healthy male dairy calves by using urinary recovery of indigestible markers (lactulose, D-mannitol, and Cr-EDTA). The replacement of lactose by monosaccharides (dextrose and galactose) served as a model to study osmolality.

\section{MATERIALS AND METHODS}

This study was conducted between October and December 2016 at the Calf Research Facility of Trouw Nutrition Research \& Development (Sint Anthonis, the Netherlands). All procedures described in this article complied with the Dutch Law on Experimental Animals, which complies with ETS123 (Council of Europe 1985 and the 86/609/EEC Directive) and were approved by the animal welfare authority (DEC Utrecht, the Netherlands).

\section{Animals and Experimental Design}

In total, 30 Holstein Friesian $(\mathrm{n}=17)$ or crossbred (with at least 40\% Holstein Friesian, $n=13$ ) male calves were acquired from dairy farms. At the farm of origin, a standardized protocol for colostrum management was applied, including 3 feedings of colostrum in the first $24 \mathrm{~h}: 3 \mathrm{~L}$ within the first $3 \mathrm{~h}$ after birth followed by 2 feedings of $2 \mathrm{~L}$. Calves were then transported to the research facility between 0 and $3 \mathrm{~d}$ after birth and the level of immunoglobulins in blood was measured within 48 to $72 \mathrm{~h}$ after birth. Mean ( \pm SEM) BW upon arrival was $44.9 \pm 1.1 \mathrm{~kg}$. All calves were fed the same experimental diet (L1, 0\% dextrose) up to 3 wk of age and were then exposed to their respective experimental diet until $7 \mathrm{wk}$ of age. Calves brought into the research 
facility in the same week were considered 1 batch (n $=6$ ). Measurement periods were then staggered as 5 batches of calves were purchased for the study. Calves were blocked based on week of arrival (batch). Within blocks, calves were randomly assigned to 1 of 5 experimental diets and exposed to their respective diet for 5 wk. Gastrointestinal permeability was assessed at 3 and 7 wk of age. The first permeability assessment was performed $3 \mathrm{~d}$ after the first exposure to treatments to evaluate the effect of a short-term exposure. The second assessment was performed at $7 \mathrm{wk}$ of age to evaluate the effect of long-term exposure (4 wk) to treatments.

\section{Housing}

Calves were housed indoors in individual pens $(1.22$ $\times 2.13 \mathrm{~m}$ ), separated by galvanized bar fences, and equipped with $50 \%$ rubber slatted floors in the front and a 50\% laying area, including a mattress covered with flax straw in the back. The minimum temperature and relative humidity in the calf facility were maintained at $15^{\circ} \mathrm{C}$ and $<80 \%$, respectively. Calves were exposed to daylight and artificial light from 0600 to $2200 \mathrm{~h}$ and to a night light during the remainder of the day.

\section{Diets and Feeding}

Five experimental diets defined a dose response with 4 levels of dextrose inclusion (replacing lactose): $0 \%$ $(\mathrm{L} 1, \mathrm{n}=5), 13.3 \%(\mathbf{L 2}, \mathrm{n}=5), 26.7 \%(\mathbf{L 3}, \mathrm{n}=5)$, and $40 \%(\mathbf{L} 4, \mathrm{n}=5)$ and an additional treatment $(\mathbf{G}+\mathbf{D}, \mathrm{n}=10)$ including $20 \%$ galactose and $20 \%$ dextrose (Figure 1). The remaining 60\% of the formula was identical for all treatments and consisted of $50 \%$ CMR fat concentrate (Trouw Nutrition, Deventer, the Netherlands), $22 \%$ milk protein concentrate, $20 \%$ whey protein concentrate $(75 \% \mathrm{CP})$, and standard mineral and vitamin CMR supplements (Trouw Nutrition, Putten, the Netherlands). Carbohydrates were exchanged based on hexose equivalents. The $\mathrm{G}+\mathrm{D}$ treatment helped distinguish whether calves were sensitive to high CMR osmolality or whether any detected effect could be caused by the replacement of galactose by dextrose at the highest level of osmolality in the study. The calculated osmolality of the CMR ranged from 439 (L1) to $611 \mathrm{mOsm} / \mathrm{kg}$ (L4 and $\mathrm{G}+\mathrm{D}$ ). The contrast between the lowest and the highest glucose inclusion level was high to allow sufficient power as well as to understand to what extent osmolality affected gastrointestinal permeability.

Nutrient composition of the treatments is shown in Table 1. Milk replacer was reconstituted with water and supplied in a teat bucket at $40^{\circ} \mathrm{C}$. Milk replacer concentration was adjusted for each treatment between $150.0 \mathrm{~g} / \mathrm{L}(\mathrm{L} 1)$ and $152.5 \mathrm{~g} / \mathrm{L}(\mathrm{L} 4$ and $\mathrm{G}+\mathrm{D})$ to standardize the carbohydrate delivery among all calves. Milk replacer was provided daily in 2 equally sized meals at 0700 and $1600 \mathrm{~h}$. Meal size was $3.2 \mathrm{~L}$ at $3 \mathrm{wk}$ of age and $3.5 \mathrm{~L}$ at $7 \mathrm{wk}$ of age. Calves were allowed to consume the milk for $15 \mathrm{~min}$, after which refusals

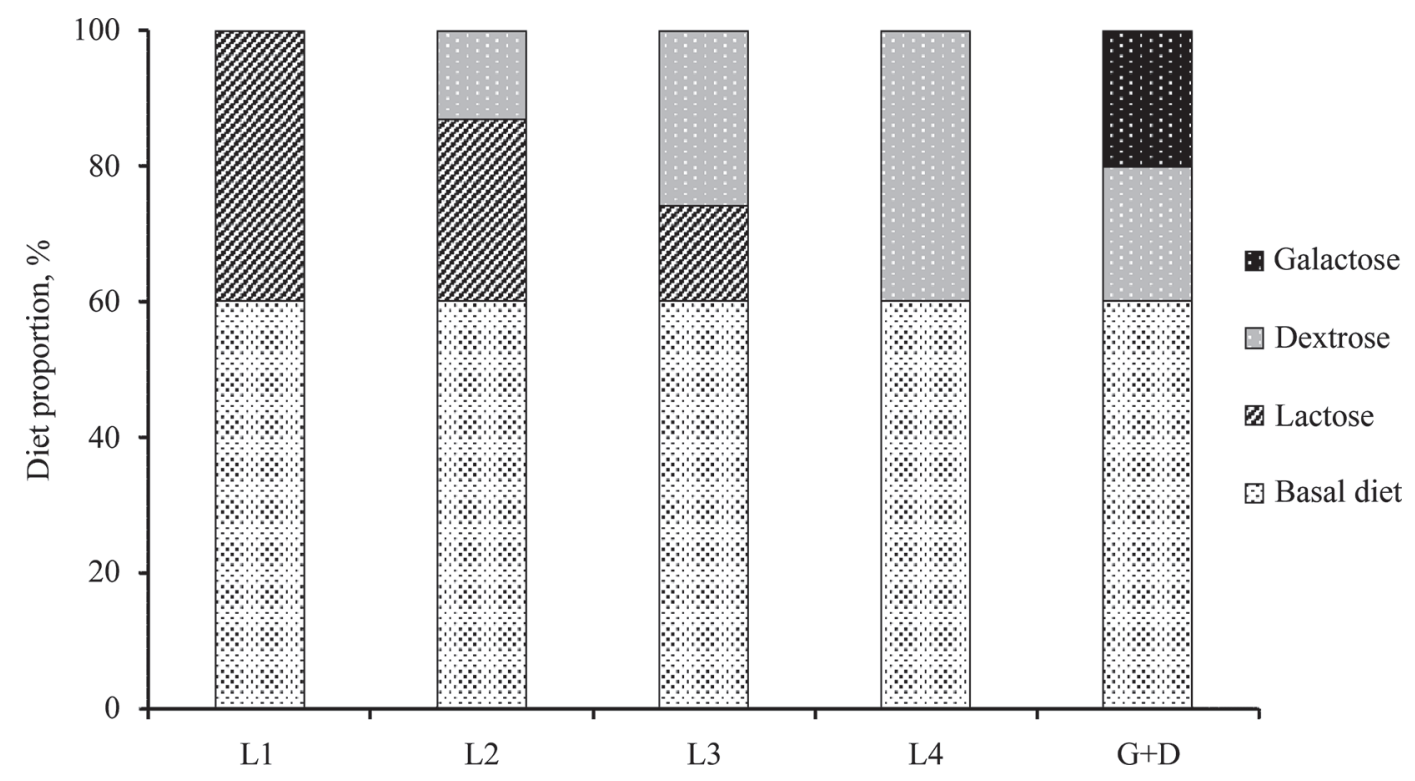

Figure 1. Schematic representation of diet formulation. Treatments included 4 levels of dextrose inclusion (replacing lactose): $0 \%$ (L1, $\mathrm{n}=$ 5), $13.3 \%(\mathrm{~L} 2, \mathrm{n}=5), 26.7 \%(\mathrm{~L} 3, \mathrm{n}=5)$, and $40 \%(\mathrm{~L} 4, \mathrm{n}=5)$ and an additional treatment $(\mathrm{G}+\mathrm{D}, \mathrm{n}=10)$ that included $20 \%$ galactose and $20 \%$ dextrose, which matched the galactose supply of L1 and the osmolality of L4. 
were withdrawn and weighed. No solids were provided throughout the study and water was offered ad libitum in buckets.

\section{Measurements}

Milk replacer components were sampled for analyses at the start of the study. Fecal spot samples were collected once weekly by manual stimulation from 3 to 7 wk of age. Gastrointestinal permeability was assessed using indigestible markers. Lactulose $(0.4 \mathrm{~g} / \mathrm{kg}$ of BW; Sigma-Aldrich, Zwijndrecht, the Netherlands), D-mannitol (0.12 g/ $\mathrm{kg}$ of BW; Sigma-Aldrich), and Cr-EDTA $(0.1 \mathrm{~g} / \mathrm{kg}$ of BW; Masterlab, Boxmeer, the Netherlands) were dissolved separately in $100 \mathrm{~mL}$ of warm water. The solutions were mixed together with the morning CMR meal at 3 and 7 wk of age. Urine was quantitatively collected during 2 periods; 0 to $6 \mathrm{~h}$ and 6 to $24 \mathrm{~h}$ after marker administration according to Branco Pardal et al. (1995). Urine was directly acidified to $\mathrm{pH} \leq 2$ with sulfuric acid to prevent microbial activity. Urine losses were estimated by visual assessment and scored from 1 to 3 ( $1=$ small loss; $2=$ large loss; $3=$ total loss).

\section{Chemical Analysis}

Samples of milk replacer were analyzed for DM, crude ash, mineral content ( $\mathrm{Na}, \mathrm{K}, \mathrm{Cl}, \mathrm{Ca}, \mathrm{P}$, and $\mathrm{Mg}$ ), carbohydrates (lactose, dextrose, and galactose), crude fat, and CP. Fecal samples were analyzed for DM and $\mathrm{pH}$. Urine samples were analyzed for minerals ( $\mathrm{Na}, \mathrm{K}$, $\mathrm{Cl}$, and $\mathrm{P}$ ), urea, creatinine, and for marker concentrations (lactulose, D-mannitol, and Cr).

All samples were processed and analyzed at Masterlab (Boxmeer, the Netherlands). The DM content was determined by drying to a constant weight in a $103^{\circ} \mathrm{C}$ stove during 4 h (EC 152/2009; EC, 2009). Crude ash was analyzed by incineration in a muffle furnace by combustion for $4 \mathrm{~h}$ at $550^{\circ} \mathrm{C}$ (EC 152/2009; EC, 2009). Crude fat was determined by treating the sample with hydrochloric acid and then extracting with petroleum (EC 152/2009; EC, 2009). Crude protein content was analyzed by combustion according to the Dumas method (Etheridge et al., 1998; ISO 16634-1; ISO, 2008a). Fecal $\mathrm{pH}$ was measured using a calibrated $\mathrm{pH}$ meter according to NEN-EN-ISO 10523 (ISO, 2008b). Carbohydrates were determined by titrimetric method according to EEG 71/250/EEG (1971) for lactose and EC 152/2009 (EC, 2009) for dextrose and galactose. Urea was analyzed by a 2-step enzymatic colorimetric analysis, hydrolyzing urea to ammonium and $\mathrm{CO}_{2}$. Ammonium ions were detected using a modified Berthelot reaction (10505, Human Diagnostics, Wiesbaden, Germany). Creatinine was analyzed by a kinetic colorimetric analyses, based upon the Jaffe reaction (10051, Human Diagnostics). Mineral content (Na, K, Ca, P, and $\mathrm{Mg}$ ) were analyzed using inductively coupled plasma

Table 1. Analyzed nutrient composition ( $\mathrm{g} / \mathrm{kg}$ of DM unless specified otherwise) of milk replacer components and treatment specifications

\begin{tabular}{|c|c|c|c|c|c|}
\hline \multirow[b]{2}{*}{ Item } & \multicolumn{5}{|c|}{ Treatment $^{1}$} \\
\hline & L1 & $\mathrm{L} 2$ & L3 & L4 & $\mathrm{G}+\mathrm{D}$ \\
\hline \multicolumn{6}{|l|}{ Nutrient } \\
\hline $\mathrm{DM}, \mathrm{g} / \mathrm{kg}$ of product & 946 & 964 & 955 & 964 & 974 \\
\hline $\mathrm{CP}$ & 225 & 230 & 225 & 222 & 221 \\
\hline Crude fat & 156 & 159 & 164 & 161 & 161 \\
\hline Lactose & 511 & 374 & 241 & 112 & 111 \\
\hline Dextrose & 0 & 113 & 244 & 370 & 184 \\
\hline Galactose & 0 & 0 & 0 & 0 & 201 \\
\hline Crude ash & 65 & 61 & 65 & 62 & 61 \\
\hline \multicolumn{6}{|l|}{ Minerals } \\
\hline $\mathrm{Na}$ & 5.8 & 5.8 & 6.2 & 5.7 & 5.5 \\
\hline $\mathrm{K}$ & 12.5 & 12.4 & 12.2 & 12.0 & 11.8 \\
\hline $\mathrm{Cl}$ & 8.0 & 7.5 & 8.3 & 7.9 & 8.0 \\
\hline $\mathrm{Ca}$ & 7.3 & 7.1 & 7.2 & 7.3 & 7.2 \\
\hline $\mathrm{P}$ & 6.8 & 6.6 & 6.6 & 6.5 & 6.4 \\
\hline $\mathrm{Mg}$ & 1.2 & 1.2 & 1.2 & 1.2 & 1.2 \\
\hline Osmolality, ${ }^{2} \mathrm{mOsm} / \mathrm{kg}$ & 439 & 497 & 553 & 611 & 611 \\
\hline
\end{tabular}

${ }^{1}$ Treatments included 4 levels of dextrose inclusion (replacing lactose): $0 \%(\mathrm{~L} 1, \mathrm{n}=5), 13.3 \%(\mathrm{~L} 2, \mathrm{n}=5)$, $26.7 \%(\mathrm{~L} 3, \mathrm{n}=5)$, and $40 \%(\mathrm{~L} 4, \mathrm{n}=5)$ and an additional treatment $(\mathrm{G}+\mathrm{D}, \mathrm{n}=10)$ that included $20 \%$ galactose and 20\% dextrose, which matched the galactose supply of L1 and the osmolality of L4.

${ }^{2}$ Osmolality (in moles per kilogram of solvent and expressed in $\mathrm{mOsm} / \mathrm{kg}$ ) was calculated according to Constable et al. (2009) by adding osmolality of carbohydrates (lactose, dextrose, and galactose) and minerals $(\mathrm{Na}, \mathrm{K}, \mathrm{Cl}, \mathrm{P}, \mathrm{Ca}$, and $\mathrm{Mg}$ ). 
mass spectrometry (ICP-MS; PerkinElmer ICP-MS 300D, PerkinElmer, Waltham, MA) according to NENEN 15510 (2017). Chloride was analyzed by a colorimetric analyses based on the improved Fried method, using mercuric 2,4,6-tripyridyl-s-triazine (DICL-250, BioAssay Systems, Hayward, CA). For the preparation of chromium measurements, $0.5 \mathrm{~mL}$ of nitric acid was added to $1 \mathrm{~mL}$ of urine sample. After a 4-h incubation at $95^{\circ} \mathrm{C}$, MilliQ water (Millipore, Billerica, MA) was added to the solution until a final volume of 15 $\mathrm{mL}$ was reached. Samples were analyzed by ICP-MS (PerkinElmer ICP-MS 300D). For the quantification of samples, a calibration curve of chromium $(0,0.005$, $0.02,0.1$, and $0.5 \mathrm{mg} / \mathrm{L}$ ) was used and the results were corrected using an internal standard (germanium 74). For the extraction of D-mannitol and lactulose, urine samples were diluted using maltitol as the internal standard. These extracts were then analyzed using a Phenomenex Luna 5u NH2 RP 18 250-mm $\times$ 4.6-mm column (Phenomenex, Utrecht, the Netherlands) on a Thermo Endura liquid chromatography tandem mass spectrometer (heated electrospray ionization source) with an Ultimate 3000 pump and autosampler (Thermo Fisher Scientific, Waltham, MA). The elution buffer was a blend of $75 \%$ acetonitrile and $25 \%$ water containing $1 \mathrm{mmol} / \mathrm{L}$ formate.

\section{Calculations and Statistical Analysis}

Based on the outcome of a study from Branco Pardal et al. (1995), for 7 calves per treatment group fed either a CMR with skimmed milk powder or a CMR with antigenic soybean flour, a standard deviation of $1.7 \%$ was assumed for Cr-EDTA urinary recovery in a 24-h urine collection period. The minimal meaningful difference between both treatments was considered to be $3.6 \%$. The minimal sample size was therefore 4 calves per treatment group. Thus, 5 calves per treatment group were used in the dose response (L1, L2, L3, and L4) and 10 calves for the $\mathrm{G}+\mathrm{D}$ treatment group.

Marker recoveries were expressed as a percentage of oral dose and assessed for the 6- and 24-h quantitative urinary collection periods. The IP index was determined as the ratio between urinary recovery (\%) of lactulose and D-mannitol (Bischoff et al., 2014). Treatments L1, L2, L3, and L4 were equally spaced in terms of lactose by dextrose exchange level (and thus osmolality). Therefore, linear and quadratic responses to dextrose inclusion were evaluated. Linear and quadratic regressions were performed to analyze the relation between lactose by dextrose exchange level and gastrointestinal permeability, as well as all other studied parameters. The $\mathrm{G}+\mathrm{D}$ diet was only compared with L4. Dependent variables were analyzed by mixed model analysis using the MIXED procedure of SAS (SAS Institute Inc., 2013).

Calf was considered the experimental unit, including treatment as fixed effect and block as random effect, and including the interaction between treatment and time. Time entered the model as a repeated statement. Body weight entered the model as covariable and was removed when $P>0.30$. Calves with large (score 2) or total (score 3) urine losses within the 24-h collection period were removed from the analysis of all parameters measured in urine. Cook's distance (D) was used as an estimate of influential data points. A general accepted cut-off rule for Cook's D is set at $4 / \mathrm{n}$. In the current study, the threshold for the regression analysis would then be $\mathrm{D}>0.24$. We decided, however, to remove only extreme measurements with $\mathrm{D}>0.4$ for the dose response analysis. Results are presented as least squares means and standard errors of the mean. Differences were considered significant at $P \leq 0.05$ and trends reported when $P \leq 0.1$.

\section{RESULTS}

Within the 24-h urine collection, 5 calves at $3 \mathrm{wk}$ of age and 2 calves at 7 wk of age had large (score 2) urine losses as estimated by visual assessment. Urinary observations for these calves were therefore excluded from the data set. In addition, 1 calf was identified as an outlier for Cr-EDTA recovery $(\mathrm{D}>0.40)$ and was removed from the regression analysis at 3 and $7 \mathrm{wk}$ of age.

\section{General Health, Urine Volume, Urine Chemistry, and Urine Electrolytes}

Osmolality and carbohydrate composition of CMR did not affect growth, fecal DM, and fecal $\mathrm{pH}$ from wk 3 to 7 of age (data not shown).

Osmolality of CMR did not affect urinary urea and creatinine or urinary electrolytes at 3 wk of age (Table 2 ). Urinary volume tended to increase and urine $\mathrm{P}$ tended to decrease with increasing osmolality at $7 \mathrm{wk}$ of age $(P<0.1)$. Urinary volume, urinary creatinine, and urea were higher for calves fed L4 compared with calves fed $\mathrm{G}+\mathrm{D}$ at 7 wk of age $(P<0.05)$.

\section{Assessment of Gastrointestinal Permeability}

Results for marker recoveries in urine are presented in Table 3. Lactulose, D-mannitol, and Cr-EDTA recoveries tended to increase for the 6 -h collection period at 3 wk of age $(P<0.1)$. For the 24 -h collection pe- 
Table 2. Effect of calf milk replacer composition on urine volume, urine chemistry, and urine minerals (LSM) in a 24-h quantitative urinary collection in healthy calves at $3(\mathrm{n}=24)$ and $7(\mathrm{n}=27)$ wk of age

\begin{tabular}{|c|c|c|c|c|c|c|c|c|c|c|}
\hline Item & $\begin{array}{l}\text { Age, } \\
\text { wk }\end{array}$ & \multicolumn{5}{|c|}{ Treatment $^{1}$} & $\begin{array}{c}\text { Pooled } \\
\text { SEM }\end{array}$ & \multicolumn{3}{|c|}{$P$-value } \\
\hline Urine volume, $\mathrm{kg}$ & 7 & 4.96 & 5.30 & 5.30 & 5.76 & 4.68 & 0.14 & 0.06 & 0.95 & 0.03 \\
\hline \multicolumn{11}{|l|}{ Urine chemistry } \\
\hline \multirow[t]{2}{*}{ Urea, g } & 3 & 12.33 & 14.50 & 10.32 & 12.83 & 12.43 & 0.62 & 0.19 & 0.98 & 0.83 \\
\hline & 7 & 15.32 & 16.56 & 17.76 & 18.05 & 14.06 & 0.50 & 0.37 & 0.78 & 0.04 \\
\hline \multicolumn{11}{|l|}{ Urine minerals } \\
\hline \multirow[t]{2}{*}{$\mathrm{Na}, \mathrm{g}$} & 3 & 4.98 & 3.59 & 4.33 & 4.05 & 4.88 & 0.20 & 0.73 & 0.36 & 0.23 \\
\hline & 7 & 4.60 & 4.34 & 4.67 & 4.93 & 5.90 & 0.22 & 0.30 & 0.92 & 0.19 \\
\hline \multirow[t]{2}{*}{$\mathrm{K}, \mathrm{g}$} & 3 & 9.87 & 10.34 & 9.64 & 10.32 & 9.55 & 0.53 & 0.57 & 0.87 & 0.42 \\
\hline & 7 & 12.59 & 10.82 & 11.90 & 11.76 & 11.15 & 0.60 & 0.70 & 0.76 & 0.55 \\
\hline \multirow[t]{2}{*}{$\mathrm{P}, \mathrm{g}$} & 3 & 1.70 & 1.80 & 1.55 & 1.64 & 1.52 & 0.06 & 0.54 & 0.78 & 0.56 \\
\hline & 7 & 1.90 & 2.05 & 1.94 & 1.82 & 1.54 & 0.07 & 0.76 & 0.42 & 0.21 \\
\hline
\end{tabular}

${ }^{1}$ Treatments included 4 levels of dextrose inclusion (replacing lactose): $0 \%$ (L1, $\mathrm{n}=5$ ), 13.3\% (L2, $\mathrm{n}=5$ ), 26.7\% (L3, $\mathrm{n}=5$ ), and 40\% (L4, $\mathrm{n}=5)$ and an additional treatment $(\mathrm{G}+\mathrm{D}, \mathrm{n}=10)$ that included $20 \%$ galactose and $20 \%$ dextrose, which matched the galactose supply of $\mathrm{L} 1$ and the osmolality of L4.

riod, lactulose $(P=0.10)$ and Cr-EDTA recoveries $(P$ $<0.05)$ increased linearly with osmolality at 3 and 7 wk of age (Figure 2). D-Mannitol recovery increased with osmolality at 3 wk of age $(P=0.05)$. Osmolality differences did not affect the IP index. Lactulose and Cr-EDTA recoveries did not differ between $\mathrm{G}+\mathrm{D}$ and L4. For the 24-h collection period, D-mannitol recovery tended to be higher for calves fed $\mathrm{G}+\mathrm{D}$ than for calves fed L4 at 7 wk of age $(P<0.1)$. The IP index was higher in calves fed L4 than in calves fed G+D at 3 wk of age $(P<0.05)$ for the 6 -h collection period but not for the 24 -h collection period.

\section{DISCUSSION}

In the current study, gastrointestinal integrity following the ingestion of hypertonic CMR was assessed in 30 healthy male dairy calves using the lactulose-

Table 3. Effect of milk replacer composition on indicators of gastrointestinal permeability (LSM) assessed by urinary recoveries of lactulose, D-mannitol, and Cr-EDTA in healthy calves at $3(\mathrm{n}=24)$ and $7(\mathrm{n}=27)$ wk of age

\begin{tabular}{|c|c|c|c|c|c|c|c|c|c|c|}
\hline Item & $\begin{array}{l}\text { Age, } \\
\text { wk }\end{array}$ & \multicolumn{5}{|c|}{ Treatment $^{1}$} & $\begin{array}{c}\text { Pooled } \\
\text { SEM }\end{array}$ & \multicolumn{3}{|c|}{$P$-value } \\
\hline \multicolumn{11}{|c|}{0 to 6 -h urine collection } \\
\hline Lactulose (L), \% & 7 & 0.72 & 0.68 & 0.89 & 0.60 & 0.75 & 0.05 & 0.82 & 0.29 & 0.42 \\
\hline \multirow[t]{2}{*}{ D-Mannitol (M), \% } & 3 & 1.30 & 1.01 & 1.98 & 2.25 & 2.79 & 0.20 & 0.08 & 0.53 & 0.33 \\
\hline & 7 & 2.35 & 1.74 & 2.78 & 1.63 & 2.50 & 0.15 & 0.59 & 0.55 & 0.12 \\
\hline Cr-EDTA, \% & 7 & 0.95 & 1.01 & 1.47 & 0.88 & 1.29 & 0.08 & 0.82 & 0.28 & 0.17 \\
\hline \multicolumn{11}{|c|}{0 to 24 -h urine collection } \\
\hline \multirow[t]{2}{*}{ Lactulose, \% } & 3 & 2.49 & 2.84 & 2.76 & 3.01 & 2.59 & 0.31 & 0.10 & 0.64 & 0.36 \\
\hline & 7 & 1.96 & 2.73 & 2.62 & 2.54 & 2.86 & 0.11 & 0.10 & 0.02 & 0.52 \\
\hline \multirow[t]{2}{*}{ D-Mannitol, \% } & 3 & 9.52 & 9.24 & 11.12 & 10.90 & 11.49 & 0.50 & 0.05 & 0.98 & 0.63 \\
\hline & 7 & 7.85 & 7.89 & 8.63 & 7.31 & 9.53 & 0.26 & 0.76 & 0.57 & 0.08 \\
\hline
\end{tabular}

${ }^{1}$ Treatments included 4 levels of dextrose inclusion (replacing lactose): $0 \%(\mathrm{~L} 1, \mathrm{n}=5$ ), $13.3 \%$ (L2, $\mathrm{n}=5$ ), 26.7\% (L3, $\mathrm{n}=5$ ), and $40 \%$ (L4, $\mathrm{n}=5)$ and an additional treatment $(\mathrm{G}+\mathrm{D}, \mathrm{n}=10)$ that included $20 \%$ galactose and $20 \%$ dextrose, which matched the galactose supply of L1 and the osmolality of L4. 
D-mannitol and Cr-EDTA permeability tests. Because no differences were detected in lactulose and Cr-EDTA recoveries between $\mathrm{L} 4$ and $\mathrm{G}+\mathrm{D}$, results suggest that the monosaccharide source in CMR (dextrose and galactose) does not affect gastrointestinal paracellular permeability. This also indicates that the observed effects of osmolality on gastrointestinal permeability are due only to osmolality differences rather than a lack of galactose or a surplus of dextrose. The greater absorption of large molecules (lactulose and Cr-EDTA) at 3 and $7 \mathrm{wk}$ of age may indicate a diminished intestinal barrier function caused by increased paracellular permeability of the gut. The results are therefore consistent with previous findings from Laker and Menzies (1977), who showed that absorption of lactulose in human subjects was significantly enhanced by increased osmolality of the test solution (from 275 to $2,000 \mathrm{mOsm} /$

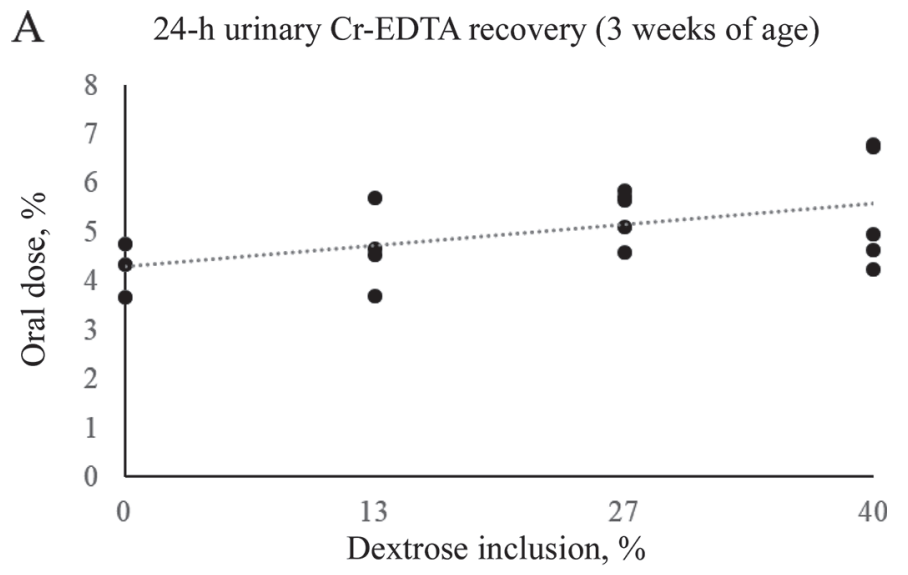

B 24-h urinary Cr-EDTA recovery (7 weeks of age)

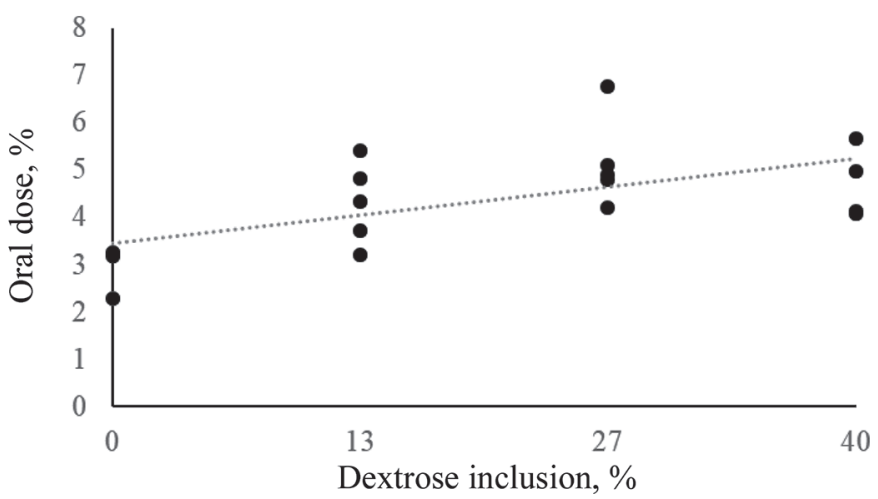

Figure 2. Chromium-EDTA urinary recovery (as \% of oral dose) during the first $24 \mathrm{~h}$ of collection after marker ingestion at $3 \mathrm{wk}(\mathrm{A})$ and $7 \mathrm{wk}(\mathrm{B})$ of age. Treatments included 4 levels of dextrose inclusion (replacing lactose): $0 \%(\mathrm{~L} 1, \mathrm{n}=5), 13.3 \%(\mathrm{~L} 2, \mathrm{n}=5), 26.7 \%(\mathrm{~L} 3, \mathrm{n}=$ $5)$, and $40 \%(\mathrm{~L} 4, \mathrm{n}=5)$ and an additional treatment $(\mathrm{G}+\mathrm{D}, \mathrm{n}=10)$ that included $20 \%$ galactose and $20 \%$ dextrose, which matched the galactose supply of L1 and the osmolality of L4. There was a significant linear regression $(P<0.05)$ at 3 and 7 wk of age $(\mathrm{n}=17)$. $\mathrm{kg}$ ). This increase in permeability to large probes has been attributed to an alteration in the condition of the intercellular tight junctions, which become leaky when exposed to hypertonic solutions (Ussing, 1966, 1969). The difference in osmolar concentration between 2 solutions determines the osmotic pressure exerted on the membrane separating them (Cronjé, 2007). The osmolality of plasma is about $300 \mathrm{mOsm} / \mathrm{kg}$, and fluids with osmolalities of about $600 \mathrm{mOsm} / \mathrm{kg}$ will therefore exert substantial osmotic pressure on the cell lining in the gut and on the tight junctions that bind them together (Cronjé, 2007). Moderate hyperosmolality may cause structural damage to the tight junction, allowing pathogens and toxins entry to the bloodstream (Kameda et al., 1968; Cronjé, 2007). Similar effects can be observed in the rumen where grain-based diets can double the osmolality of rumen digesta, leading to an increase in the osmotic pressure gradient between the gut circulation and the rumen content (Cronjé, 2005). This results in rapid movement of water from the blood across the rumen epithelium, causing epithelial cells to separate from the basement membrane and therefore compromising barrier function (Cronjé, 2005).

In addition to the possible diminished gastrointestinal barrier function, hypertonic solutions (>300 mOsm/kg) have been associated with a delayed abomasal emptying rate (Bell and Razig, 1973; Sen et al., 2006; Pearson et al., 2013), which was shown to increase the incidence of gastrointestinal diseases in calves (Glenn Songer and Miskimins, 2005; Burgstaller et al., 2017). In the present study, osmolality of milk replacer (up to 611 $\mathrm{mOsm} / \mathrm{kg}$ ) did not affect the health of the calves. The study was not, however, designed to detect differences in growth or diarrhea incidence. Results for fecal DM are consistent with previous findings of Azevedo et al. (2016), in which hypertonic CMR (up to $533 \mathrm{mOsm} /$ $\mathrm{kg}$ ) did not affect fecal scores.

Recoveries of lactulose and D-mannitol as well as IP index found herein for the 6-h collection are in the range of those reported by Klein et al. (2007, 2008), but lower than those reported by Branco Pardal et al. (1995; Table 4). For the 6-h collection period, calves in the current study had an IP index between 0.23 and 0.40. According to Klein et al. (2007), the IP index for a healthy calf fed raw bovine milk is $0.25 \pm 0.05$ and that of diarrheic calves about $0.59 \pm 0.12$. The IP index is a useful indicator in case of reduction of the absorptive surface area occurring, for example, following the ingestion of enterotoxic drugs (Klein et al., 2007) or during diarrhea (Klein et al., 2008). It might not be as indicative, however, when excretion of both markers (large and small probe molecules) is increased to the same extent as in the present study. Lactulose recovery in the 6 -h collection period was $0.40 \%$ for calves fed 
WILMS ET AL.

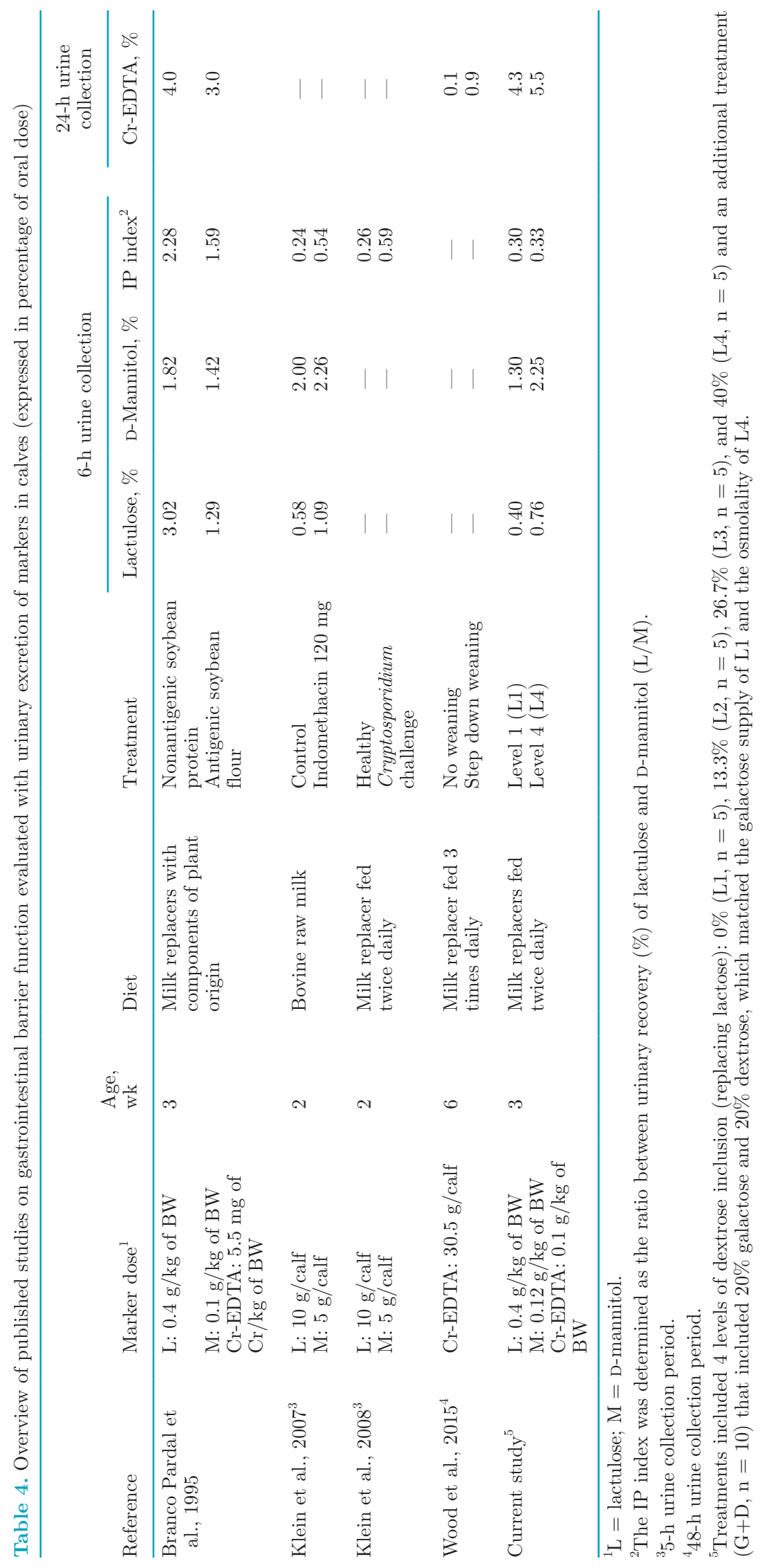


L1 (439 mOsm $/ \mathrm{kg})$ and $0.76 \%$ for calves fed L4 (611 $\mathrm{mOsm} / \mathrm{kg}$ ) at $3 \mathrm{wk}$ of age. Comparatively, Klein et al. (2007) reported a lactulose recovery of $0.58 \%$ for calves fed raw bovine milk and $1.09 \%$ for calves challenged with an enterotoxic drug (120 mg of indomethacin; Table 4). Urinary recovery of Cr-EDTA in the 24-h collection period was 22 and $37 \%$ higher in calves fed L4 than in those fed L1 at 3 and 7 wk of age, respectively. Similarly, urinary recovery of lactulose was 17 and $23 \%$ higher in calves fed L4 than in those fed L1 at 3 and 7 wk of age, respectively. Hypertonic milk replacers (>600 mOsm $/ \mathrm{kg}$ ) therefore induce a significant increase in gastrointestinal permeability, which might be of clinical relevance as gut permeability is maintained in a narrow range (Table 4 ).

The model for increased osmolality of milk replacer used in this study was induced by the gradual replacement of lactose by dextrose and galactose. This model might not, however, be representative of increased osmolality of milk replacer induced by an elevation of mineral content or of the concentration of the solution. In addition, as all calves were fed L1 for the first $2 \mathrm{wk}$ of life, the observed effects of the experimental diets on gastrointestinal permeability could be due to the change in diet from wk 2 to wk 3 of age. However, because the effect of treatment was also detected at 7 wk of age, it is likely that the observed differences in gastrointestinal permeability were induced by the osmolality differences of the milk replacer itself. Further investigations carried out on a large number of animals are needed to evaluate the clinical implications for calf health, if any, of the observed differences.

\section{CONCLUSIONS}

Increasing osmolality of calf milk replacer by exchanging lactose with dextrose affected gastrointestinal permeability. In the $24-\mathrm{h}$ urine collection period, we observed elevations of about 20 to $30 \%$ in lactulose and Cr-EDTA recovery between calves fed milk replacers with an osmolality increasing from 439 to $611 \mathrm{mOsm} /$ $\mathrm{kg}$. Because these permeability tests are indicative of macroscopic mucosal damages, hypertonicity of milk replacer can be considered as a potential risk factor for calf health.

\section{ACKNOWLEDGMENTS}

The authors thank Natasja Boots, Simon Lacombe, Guanlin Wang, Annemiek Welboren, and the personnel of the Trouw Nutrition's Calf Research Facility (Sint Anthonis, the Netherlands) for their technical assistance.

\section{REFERENCES}

Andre, C., F. Andre, L. Colin, and S. Cavagna. 1987. Measurement of intestinal permeability to mannitol and lactulose as a means of diagnosing food allergy and evaluating therapeutic effectiveness of disodium cromoglycate. Ann. Allergy 59:127-130.

Araujo, G., C. Yunta, M. Terré, A. Mereu, I. Ipharraguerre, and A. Bach. 2015. Intestinal permeability and incidence of diarrhea in newborn calves. J. Dairy Sci. 98:7309-7317.

Azevedo, R. A., F. S. Machado, M. M. Campos, D. R. G. Lopes, S. F. Costa, H. C. Mantovani, F. C. F. Lopes, M. I. Marcondes, L. G. R. Pereira, T. R. Tomich, and S. G. Coelho. 2016. The effects of increasing amounts of milk replacer powder added to whole milk on passage rate, nutrient digestibility, ruminal development, and body composition in dairy calves. J. Dairy Sci. 99:8746-8758.

Baumgard, L. H., and R. P. Rhoads. 2013. Effects of heat stress on postabsorptive metabolism and energetics. Annu. Rev. Anim. Biosci. 1:7.1-7.27

Bell, F. R., and S. A. D. Razig. 1973. Gastric emptying and secretion in the milk-fed calf. J. Physiol. 228:499-512.

Bischoff, S. C., G. Barbara, W. Buurman, T. Ockhuizen, J. D. Schulzke, M. Serino, H. Tilg, A. Watson, and J. M. Wells. 2014. Intestinal permeability-A new target for disease prevention and therapy. BMC Gastroenterol. 14:189.

Branco Pardal, P., J. P. Lallès, F. André, E. Delval, and R. Toullec. 1995. Assessment of gastrointestinal permeability to small marker probes in the preruminant calf. Reprod. Nutr. Dev. 35:189-200.

Burgstaller, J., T. Wittek, and G. W. Smith. 2017. Invited review: Abomasal emptying in calves and its potential influence on gastrointestinal disease. J. Dairy Sci. 100:17-35.

Cerbulis, J., and H. M. Farrell. 1976. Composition of the milks of dairy cattle. II. Ash, calcium, magnesium, and phosphorus. J. Dairy Sci. 59:589-593.

Constable, P. D., W. Grünberg, and L. Carstensen. 2009. Comparative effects of two oral rehydration solutions on milk clotting, abomasal luminal $\mathrm{pH}$, and abomasal emptying rate in suckling calves. J. Dairy Sci. 92:296-312.

Cronjé, P. B. 2005. Heat stress in livestock-The role of the gut in its aetiology and a potential role for betaine in its alleviation. Recent Adv. Anim. Nutr. Aust. 15:107-122.

Cronjé, P. B. 2007. Gut health, osmoregulation and resilience to heat stress in poultry. Pages 9-13 in Aust. Poult. Sci. Symp., Sydney, New South Wales. Poultry Research Foundation, Faculty of Veterinary Science, University of Sydney, Camden, NSW, Australia.

Davies, D. T., and J. C. D. White. 1960. The use of ultrafiltration and dialysis in isolating the aqueous phase of milk and in determining the partition of milk constituents between the aqueous and disperse phases. J. Dairy Res. 27:171-190.

EC. 2009. No 152/2009. Commission regulation laying down the methods of sampling and analysis for the official control of feed. Off. J. Eur. Union L 54:1-130.

EEG 71/250/EEG. 1971. Methods of analysis for the official control of feeding stuffs. Official Journal of the European Union. L 155:13.

Etheridge, R., G. Pesti, and E. Foster. 1998. A comparison of nitrogen values obtained utilizing the Kjeldahl nitrogen and Dumas combustion methodologies (Leco CNS 2000) on samples typical of an animal nutrition analytical laboratory. Anim. Feed Sci. Technol. $73: 21-28$.

Floren, H. K., W. M. Sischo, C. Crudo, and D. A. Moore. 2016. Technical note: Use of a digital and an optical Brix refractometer to estimate total solids in milk replacer solutions for calves. J. Dairy Sci. 99:7517-7522.

Glenn Songer, J., and D. W. Miskimins. 2005. Clostridial abomasitis in calves: Case report and review of the literature. Anaerobe $11: 290-294$.

Glosson, K. M., B. A. Hopkins, S. P. Washburn, S. Davidson, G. Smith, T. Earleywine, and C. Ma. 2015. Effect of supplementing pasteurized milk balancer products to heat-treated whole milk on the growth and health of dairy calves. J. Dairy Sci. 98:1127-1135. 
Goldblum, O. M., I. R. Holzman, and S. E. Fisher. 1981. Intragastric feeding in the neonatal dog: Its effect on intestinal osmolality. Am. J. Dis. Child. 135:631-633.

Hall, E. J., and R. M. Batt. 1991. Differential sugar absorption for the assessment of canine intestinal permeability: The cellobiose/ mannitol test in gluten-sensitive enteropathy of Irish setters. Res. Vet. Sci. 51:83-87.

ISO. 2008a. Food products - Determination of the total nitrogen content by combustion according to the Dumas principle and calculation of the crude protein content-Part 1: Oilseeds and animal feeding stuffs. ISO 16634-1:2008. International Organization for Standardization, Geneva, Switzerland.

ISO. 2008b. Water quality-Determination of pH. NEN-EN-ISO 10523:2008. ISO, Geneva, Switzerland.

Jalonen, T. 1991. Identical intestinal permeability changes in children with different clinical manifestations of cow's milk allergy. J. Allergy Clin. Immunol. 88:737-742.

Kameda, H., T. Abei, S. Nasrallah, and F. L. Iber. 1968. Functional and histological injury to intestinal mucosa produced by hypertonicity. Am. J. Physiol. 214:1090-1095.

Kertz, A. F., and J. R. Loften. 2013. Review: A historical perspective of specific milk-replacer feeding programs in the United States and effects on eventual performance of Holstein dairy calves. Prof. Anim. Sci. 29:321-332.

Khafipour, E., D. O. Krause, and J. C. Plaizier. 2009. A grain-based subacute ruminal acidosis challenge causes translocation of lipopolysaccharide and triggers inflammation. J. Dairy Sci. 92:10601070 .

Klein, P., T. Kleinová, Z. Volek, and J. Šimůnek. 2008. Effect of Cryptosporidium parvum infection on the absorptive capacity and paracellular permeability of the small intestine in neonatal calves. Vet. Parasitol. 152:53-59

Klein, P., J. Moravcová, T. Kleinová, Z. Volek, and V. Skřivanová 2007. Assessment of intestinal permeability in preruminant calves by lactulose/mannitol test. J. Anim. Feed Sci. 16:43-52.

Kvidera, S. K., E. A. Horst, M. Abuajamieh, E. J. Mayorga, M. V. Sanz Fernandez, and L. H. Baumgard. 2017. Glucose requirements of an activated immune system in lactating Holstein cows. J. Dairy Sci. 100:2360-2374.

Laker, M. F., and I. S. Menzies. 1977. Increase in human intestinal permeability following ingestion of hypertonic solutions. J. Physiol. 265:881-894.

Mani, V., T. E. Weber, L. H. Baumgard, and N. K. Gabler. 2012 Growth and Development Symposium: Endotoxin, inflammation, and intestinal function in livestock. J. Anim. Sci. 90:1452-1465.

McGuirk, S. M. 2003. Solving calf morbidity and mortality problems. Am. Assoc. Bovine Pract., Columbus, OH. https://www.vetmed wisc.edu/dms/fapm/fapmtools/8calf/calfmorbid.pdf.

Minuti, A., S. Ahmed, E. Trevisi, F. Piccioli-Cappelli, G. Bertoni, N. Jahan, and P. Bani. 2014. Experimental acute rumen acido- sis in sheep: Consequences on clinical, rumen, and gastrointestinal permeability conditions and blood chemistry. J. Anim. Sci. 92:3966-3977.

Moeser, A. J., C. V. Klok, K. A. Ryan, J. G. Wooten, D. Little, V. L. Cook, and A. T. Blikslager. 2007. Stress signaling pathways activated by weaning mediate intestinal dysfunction in the pig. Am. J. Physiol. Gastrointest. Liver Physiol. 292:G173-G181.

NEN-EN 15510. 2017. Animal feeding stuffs: Methods of sampling and analysis-Determination of calcium, sodium, phosphorus, magnesium, potassium, iron, zinc, copper, manganese, cobalt, molybdenum and lead by ICP-AES. Official Journal of the European Union.

Norris, H. T. 1973. Response of the small intestine to the application of a hypertonic solution. Am. J. Pathol. 73:747-764.

Pearce, S. C., V. Mani, T. E. Weber, R. P. Rhoads, J. F. Patience, L. H. Baumgard, and N. K. Gabler. 2013. Heat stress and reduced plane of nutrition decreases intestinal integrity and function in pigs. J. Anim. Sci. 91:5183-5193.

Pearson, F., M. J. Johnson, and A. A. Leaf. 2013. Milk osmolality: Does it matter? Arch. Dis. Child. Fetal Neonatal Ed. 98:F166F169

Quigg, J., G. Brydon, A. Ferguson, and J. Simpson. 1993. Evaluation of canine small intestinal permeability using the lactulose/rhamnose urinary excretion test. Res. Vet. Sci. 55:326-332.

SAS Institute Inc. 2013. SAS/STAT(R) 9.4 User's Guide. SAS Institute Inc., Cary, NC.

Sen, I., P. D. Constable, and T. S. Marshall. 2006. Effect of suckling isotonic or hypertonic solutions of sodium bicarbonate or glucose on abomasal emptying rate in calves. Am. J. Vet. Res. 67:13771384

Szabo, J. S., and J. E. Fewell. 1990. Small intestinal myoelectric activity in healthy neonatal piglets: Effects of hyperosmolal formula. J Pediatr. Gastroenterol. Nutr. 11:101-108.

Turner, M. W., P. Boulton, J. G. Shields, S. Strobel, S. Gibson, H. R. Miller, and R. J. Levinsky. 1988. Intestinal hypersensitivity reactions in the rat. I. Uptake of intact protein, permeability to sugars and their correlation with mucosal mast-cell activation. Immunology $63: 119-124$.

Ussing, H. H. 1966. Anomalous transport of electrolytes and sucrose through isolated frog skin induced by hypertonicity of the outside bathing solution. Ann. N. Y. Acad. Sci. 137:543-555.

Ussing, H. H. 1969. The interpretation of tracer fluxes in terms of membrane structure. Q. Rev. Biophys. 1:365-376.

Wood, K. M., S. I. Palmer, M. A. Steele, J. A. Metcalf, and G. B. Penner. 2015. The influence of age and weaning on permeability of the gastrointestinal tract in Holstein bull calves. J. Dairy Sci. 98:7226-7237. 